\title{
Disparities in the Induced Rain Attenuation between Beacon (Narrowband) and Broadband Satellite Links in Tropical Zones
}

\author{
Idrissa Abubakar', Jafri Din*2, Hong Yin Lam³ \\ 1,2 Wireless Communications Centre, Faculty of Electrical Engineering, Universiti Teknologi Malaysia, Skudai 81310. \\ ${ }^{3}$ Department of Electrical Engineering, Technology, Faculty of Engineering Technology, Universiti Tun Hussein Onn \\ Malaysia Parit Raja, Batu Pahat 86400 Johor, Malaysia. \\ ${ }^{1,3}$ Satellite Network Operations Centre (NOC), Nigerian Communication Satellite Ltd, Obasanjo Space Center Abuja,
} Nigeria.

\section{Article Info \\ Article history: \\ Received Nov 19, 2017 \\ Revised Jan 25, 2018 \\ Accepted Feb 12, 2018}

\section{Keywords:}

Availability

Beacon signal

Broadband signal

Rain Attenuation

VSATs

\begin{abstract}
The utilisation of higher frequency bands above $10 \mathrm{GHz}$ by the satellite industries to provide the bandwidth (BW) required for broadband multimedia services, video conferencing, direct-to-home TV programmes and IP data requires the understanding of atmospheric losses and good link planning for satellite-to-earth links. The trade-off between the service availability, data rate and $\mathrm{BW}$ determine the type of modulation scheme and error corrections to be employed. These services also depend on the link performance under adverse atmospheric conditions, especially rain-induced attenuation. In this research, study measurements were conducted on space-to-earth satellite links using the beacon narrowband and broadband IP carrier signals of a Nigcomsat-1R satellite operating at $42.5^{\circ} \mathrm{E}$. A VSAT receiving terminal at a latitude of $7.4^{\circ} \mathrm{N}$, longitude of $9.04^{\circ} \mathrm{E}$ and altitude of $334 \mathrm{~m}$ above sea level was utilised to quantify the rain-induced attenuation of both the beacon and broadband signals during rain events. The measurements were then compared with the link performance under clear sky conditions. The performance revealed that, when compared with the broadband signal, the induced rain attenuation on beacon signal presented a disparity in the responses, resulting in significant variations of $10.14 \mathrm{~dB}$ in the carrier-tonoise ratio $(\mathrm{C} / \mathrm{N})$ and $17.42 \mathrm{~dB}$ in the received signal level at a Ku-band frequency of $12.518 \mathrm{GHz}$. These observations were also compared with the Crane global rain map and ITU-R P.618-12. Both models disagreed with the measurement values for Abuja, Nigeria.
\end{abstract}

Copyright $@ 2018$ Institute of Advanced Engineering and Science. All rights reserved.

\section{Corresponding Author:}

Jafri Din,

Wireless Communications Centre, Faculty of Electrical Engineering,

Universiti Teknologi Malaysia,

Skudai 81310

Email: jafri@utm.my

\section{INTRODUCTION}

Broadband multimedia satellite application services require the use of a high bandwidth (BW) capacity to deliver the required data rate, especially for wireless communications systems and satellite communication networks. This can only be achieved at a higher frequency due to the high-capacity transponder BW in such a system. Conversely, signal propagation at higher frequencies is susceptible to atmospheric degradation because of their shorter wavelengths when colliding with rain drops along the propagation path, either by the scattering effect or total absorption of the carrier signal. Hence, there is a need for appropriate migration techniques for signals at frequencies above $10 \mathrm{GHz}$. Several propagation experiments have been performed to measure or characterise and model these propagation effects in both temperate and tropical regions; however, the challenges remain critical. The first propagation experiment 
using satellite beacons was conducted by National Aeronautic and Space Administration (NASA) with Application Technology Satellite ATS-5 and ATS-6 satellites in the 1970s, while many more are still being conducted by both academic research groups and telecommunications industry development groups.

Propagation campaigns have continued using different satellites, including INTELSAT satellite fleets, which are mostly employed in the United States, Japan and Europe, covering the temperate region. Different research campaigns have also been conducted using other satellite sources; however, these could not provide total global coverage. Among the satellites used for propagation studies are the COMSTAR, ETS-II, SIRIO, CS, OLYMPUS, ASTRA-2B, SES, KOREASATs, WINDS and SARACUS satellites. Similar campaigns have been undertaken with some commercial satellites, with either on-board or groundbased generated beacon signals from the control stations; for instance, SINOSATs, INDOSAT, NIGCOMSATs, TUKSAT and BELINTELSAT-1 have been involved in propagation measurement missions. Among commercial satellite companies, beacon signals are mostly used as the reference signals, with an unmodulated or continuous wave $(\mathrm{CW})$ carrier with a fixed frequency and power. In opposition to beacon satellites, broadband application carriers are generally information-modulated signals with certain defined transmission rates (TR) in bits per second (bps) occupying a certain BW at an assigned transmit power. For this reason, it is necessary to evaluate the performance of both the beacon and broadband signal relative to the same atmospheric conditions to compare the induced attenuation for the appropriate link margin. This will help the satellite operators in determining the type of fade mitigation technique and provide for the appropriate link design relative to the BW capacity requirements.

Several rain attenuation models have been proposed, including those recommended by ITU-R study groups for the prediction of rain attenuation in satellite system design; nevertheless, most of these models disagree with the real-time performance measurements in tropical regions with heavy rainfall. In practice, satellite communication signals are modulated carriers, differing from beacon CW carriers in the required BW and power for a certain data rate to be achieved. The percentage of service availability above $99 \%$ and the quality of service, modulation scheme and error corrections are of equal concern in broadband signals, which are not considered for beacons.

Satellite service applications are generally concerned with the delivery of information traffic, such as voice connectivity in voice over IP (VOIP), direct-to-home TV, video on demand for real-time conferencing and interactive multimedia sessions. These can only be achieved using broadband, and hence, there is a need for link performance assessment. A beacon signal, in contrast, is a narrowband signal transmission at a single point frequency. Satellite beacons have vital applications in satellite tracking and telemetry services in mission-critical operations, navigation systems, fleet management and global positioning, especially when used in the L-band frequency. In most cases, satellite beacons perform reliably even in bad weather conditions, including rain. However, they may not be reliable enough for link analysis carrying broadband data traffic.

Studies have also shown that link availability is critical for the overall performance of satellite communications systems, which is equally a function of carrier power to the system's spectral noise density ratio (carrier-to-noise ratio, $\mathrm{C} / \mathrm{N}$ ) relating to information quality for radiofrequency (RF) signals in terms of the data rate, video quality or audio fidelity [1]. Thus, the challenges of rain attenuation will require a different approach, since prediction and measurements using beacons has not performed optimally to mitigate the propagation impairments enough to compensate for the rain effect [2]. Beacon signals from ACTS satellites were similarly used for propagation research experiments, while beacons have principally been used for pointing and tracking in commercial satellite applications. They are also used for the 1-dB power compression reference during uplink power control (UPC) systems and high-power amplifier (HPA) saturation control (input and output back-off) for broadband data transmission, as provided in the NigComSat-1R satellite.

Nigeria and the West African sub-region are covered by the footprint of the Nigcomsat-1R satellite, and they are situated in the heavy rain zone shown in Figure 2a in the global rain map's rain zones N and P. These zones mostly experience a combination of convective and stratiform rain types, giving rise to a high rain rate, longer event duration and wider coverage radius [3]. While some measurements agree with the models in some studies, none have been compared with industry practice for either link budgets or broadband application services. Therefore, comparisons for fade mitigations should be based on the similarity in the application and type of services provided.

\subsection{Rain Attenuation and Satellite Links}

Satellite links' response to rain attenuation defines the performance stability and percentage of time availability. Satellite-to-earth $\mathrm{CW}$ beacon signals and broadband downlink attenuation measurements using VSAT terminals at a Ku-band frequency were set up for evaluation. The parameters affected by the rain during signal propagation are the $\mathrm{C} / \mathrm{N}$ for the $\mathrm{RF}$ signal, where higher values of $\mathrm{C} / \mathrm{N}$ provide better link 
performance, and bit error rate (BER) for digital systems due to the loss of energy in the link, in which a lower BER results in better link performance. [4].

In satellite industry practice, link availability, rain attenuation and duration of outage determine the terms of service when subscribing to satellite transponders operating at higher frequencies of the Ku-band and above. The uplink to downlink composite losses from rain effects varies with the geographic location and local weather profile relative to the point rain rate and distribution [4].

\subsection{The ITU-R P.618-12 Rain Attenuation Model}

The ITU-R P.618-12 rain attenuation model requires the computation of a rainfall rate at $0.1 \%$ to $0.001 \%$ of time availability when the link is interrupted by a rain event for a given location for comparison between the prediction and measurement results to estimate attenuation due to rain [5]. The estimates of attenuation for the long-term statistics along the slant path of satellite-to-earth attenuation at any location for frequencies from $4-55 \mathrm{GHz}$ are made using the following equation:

$$
\gamma_{R}=k\left(R_{0.01}\right)^{\alpha}[\mathrm{dB} / \mathrm{km}]
$$

\subsection{ITU-R P.837-7 Rain Rate Model}

This prediction method calculates the rainfall rate exceeded for a desired annual average probability for time exceedance and a given location on the surface of the Earth using digital maps of the monthly total rainfall and monthly mean surface temperature. The annual rainfall rate data exceeded for $0.01 \%$ of an average year, R0.01 ( $\mathrm{mm} / \mathrm{h})$, is also an integral part of this recommendation, and these data are available as digital maps.

Input parameters:

1. p: Desired annual probability of exceedance $(\%)$;

2. Lat: Latitude of the desired location (degrees, N); and

3. Lon: Longitude of the desired location (degrees, E).

Output parameter: Rp: Rainfall rate exceeded for the desired probability of exceedance $(\mathrm{mm} / \mathrm{h})$.

For each month number ii, convert Tii (K) to tii $\left({ }^{\circ} \mathrm{C}\right)$.

For each month number ii, calculate rii as follows:

For each month number ii, calculate the monthly probability of rain as follows:

$$
P_{0 i i}=100 \frac{M T_{i i}}{24 * N_{i i} * r_{i i}}(\%)
$$

For each month number ii, where ii $=\{01,02,03,04,05,06,07,08,09,10,11$ and 12 $\}$, the monthly mean total rainfall, MTii (mm), at the desired location (Lat, Lon) has been determined from long-term local data.

\subsection{Application of Satellite Beacons}

A satellite beacon is a single point fixed-frequency, fixed-power, unmodulated CW carrier radiated from the satellite. Beacons are used for different applications, ranging from telemetry and tracking in space missions to Earth atmospheric effects and mitigation studies. Commercial communication satellites use beacon signals for pointing and tracking satellite position, navigation, fleet management and optical experiments for medical research in deep space missions [9]. When accessing satellite resources, beacon signals are generally used for pointing the earth-station terminal to the satellite of interest. Beacon signals can also identify the presence of rain fade for automatic uplink power control (AUPC) for reference [10].

A satellite beacon can be an on-board CW signal or ground based, as in the case of the NigComSat1R system, where the beacon was transmitted as a CW (RF) carrier at a 14-GHz uplink using an Agilent E8257D signal generator. The uplink in horizontal polarisation is at $14 \mathrm{GHz}$, and the vertical downlink is at $12 \mathrm{GHz}$ [9-10]. The beacon signal even operates optimally in adverse weather conditions, making it a good reference for earth-station pointing and tracking. Rain-induced attenuation in a Ku-band beacon is usually estimated at 1-5 dB; however, due to the local climatology and rain rate (R0.01), this is not realistic for tropical rain regions [9]. The beacon signal stability in Figure 1 is in the range of $\pm 2 \mathrm{~dB}$; this was measured at the propagation site of the University Teknologi Malaysia (UTM) campus. 


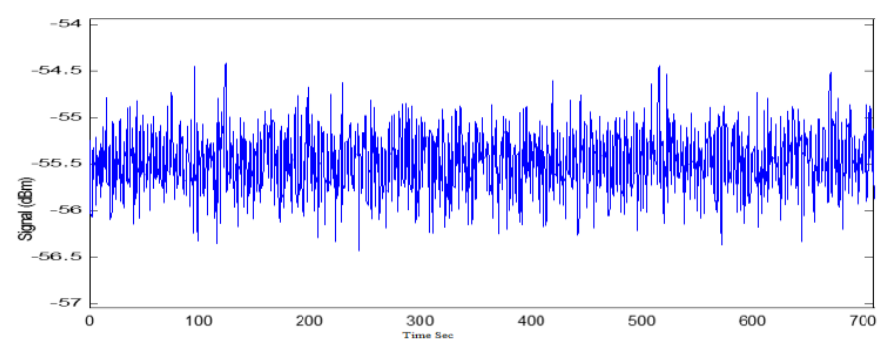

Figure 1. Continuous wave (CW) Beacon Signal Showing a Stability of $2 \mathrm{~dB}$, Measured at University Teknologi Malaysia (UTM), Johor Bahru, Malaysia.

The received beacon signal in Figure 1 shows the stability of the beacon signal during rain events measured at UTM, Johor Bahru, Malaysia, sampled at rates of $0.5 \mathrm{~Hz}$ and $1 \mathrm{~Hz}$ for fade dynamic analysis. This shows the stability of the beacon within $2 \mathrm{~dB}$, even during wet events [10], illustrating that the level of attenuation is low compared with the link outages of direct broadcast satellite (DBS) television services.

\subsection{Induced Attenuation on a Composite Link}

A composite link comprises uplink and downlink loops along the return path of the satellite transmission network. The path losses induced along the return link due to atmospheric noise, including thermal and system sources [7], also contribute to link degradations and induced attenuation when comparing measurements and predictions for the link budget. SatMaster-Pro is a link budget software program that is commonly used to calculate the link budget and path losses to provide the link margin by satellite internet service providers (ISPs). These combined propagation path effects are presented in Tables 1, 2 and 3, using the ITU-R rain rate model value, Crane global map rain zones and rain gauge-measured rain rate, respectively. The output shows considerable variations in rain-induced attenuation, as follows: $21.84 \mathrm{~dB}$, $18.75 \mathrm{~dB}$ and $26.57 \mathrm{~dB}$. This also demonstrates that rain-induced attenuation varies with the rain rate.

For the Nigcomsat-1R composite links, the following satellite parameters were considered relative to the local climatology [8]:

1. Nigcomsat-1R parameters: satellite position $=42.5^{\circ} \mathrm{E}$, operating frequency $=14 / 12 \mathrm{GHz}$, polarisation $=$ 90;

2. Rain models used: ITU-R $=100 \mathrm{~mm} / \mathrm{h}$, crane $=90 \mathrm{~mm} / \mathrm{h}$, rain gauge measured $=140.0 \mathrm{~mm} / \mathrm{h}$, percentage availability $=99.98 \%$; and

3. Total system noise: $290 \mathrm{~K}$; look angle $=47.83^{\circ}$; true satellite azimuth $=102.72^{\circ}$; path distance to satellite $=37,217.41 \mathrm{~km}$.

The ITU-R P.837-7 rain model presented a rain rate of $100 \mathrm{~mm} / \mathrm{h}$, while according to the Crane global rain $\mathrm{map}$, it is $90 \mathrm{~mm} / \mathrm{h}$ (Figure $\mathrm{lb}$ ). However, the measured rain rate using the RG3-M rain gauge presents 140 $\mathrm{mm} / \mathrm{h}$, which shows that both the ITU-R and Crane models underestimate the rain rate for Abuja, Nigeria. Similar disparity was observed with (Figure 2a) showing variation from $90 \mathrm{~mm} / \mathrm{h}$ to $140 \mathrm{~mm} / \mathrm{h}$ (Figure 2b). This disparity motivated the present study, as their prediction did not show satisfactory consistency.

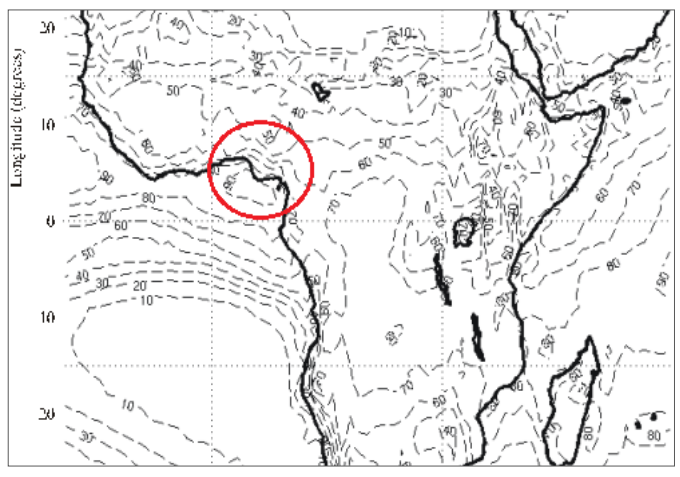

Figure 2a. Global Rain Map Showing Nigeria at $90 \mathrm{~mm} / \mathrm{h}$.

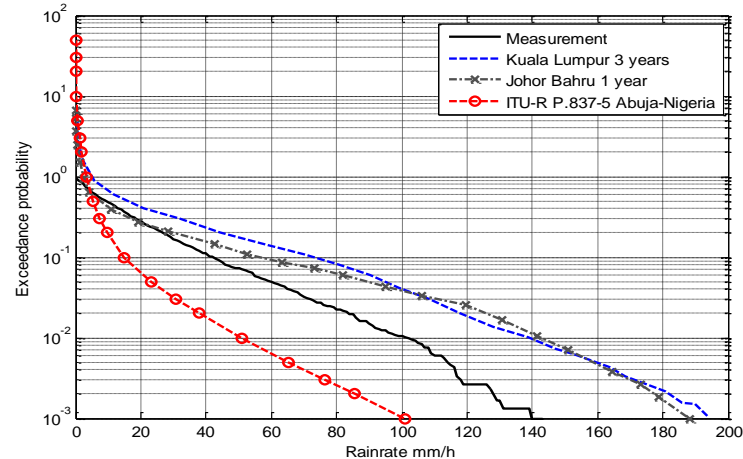

Figure 2b. CCDF of Measured Rain rate Showing 140 $\mathrm{mm} / \mathrm{h}$, against the ITU-R Model of $100 \mathrm{~mm} / \mathrm{h}$. 
From the complementary cumulative distribution function (CCDF) in Figure 2b, ITU-R P.837-7 provided an estimate of $100 \mathrm{~mm} / \mathrm{h}$ for Abuja, Nigeria, while the measurements presented $140 \mathrm{~mm} / \mathrm{h}$. These parameters were then applied to the SatMaster-Pro satellite industry simulation software, and the results are presented in Tables 1, 2 and 3, with higher attenuation values corresponding to higher rain rates. For the satellite-to-earth evaluation, only the downlink signal was measured for both the beacon and broadband link.

Table 1. ITU-R Rain Model with a Rain Rate of $100 \mathrm{~mm} / \mathrm{h}$

\begin{tabular}{ccc}
\hline Parameter & Value & Unit \\
\hline Rain attenuation & 21.84 & $\mathrm{~dB}$ \\
Total attenuation & 23.14 & $\mathrm{~dB}$ \\
Availability (average year) & 99.99 & $\%$ \\
\hline
\end{tabular}

Table 2. Crane Global Rain Model with a Rain Rate of $90 \mathrm{~mm} / \mathrm{h}$

\begin{tabular}{ccc}
\hline Parameter & Values & Unit \\
\hline Rain attenuation & 18.75 & $\mathrm{~dB}$ \\
Total attenuation & 20.05 & $\mathrm{~dB}$ \\
Availability (average year) & 99.99 & $\%$ \\
\hline
\end{tabular}

Table 3. Rain Gauge--measured Point Rain Rate of $140 \mathrm{~mm} / \mathrm{h}$

\begin{tabular}{ccc}
\hline Parameter & Value & Unit \\
\hline Rain attenuation & 26.57 & $\mathrm{~dB}$ \\
Total attenuation & 27.87 & $\mathrm{~dB}$ \\
Availability (average year) & 99.99 & $\%$ \\
\hline
\end{tabular}

In the comparison, the rain attenuation varies with the rain rate. The ITU-R model with a rain rate of $100 \mathrm{~mm} / \mathrm{h}$ produces attenuation of $21.84 \mathrm{~dB}$, Crane with a rain rate of $90 \mathrm{~mm} / \mathrm{h}$ presents $18.75 \mathrm{~dB}$ and the rain gauge-measured point rain rate of $140 \mathrm{~mm} / \mathrm{h}$ produces an attenuation of $26.57 \mathrm{~dB}$.

\section{RESEARCH METHOD}

Two separate experimental setups were considered, as shown in Figure 3, to ascertain the performance of beacon $\mathrm{CW}$ signals in terms of the $\mathrm{C} / \mathrm{N}$ and receive signal level $(\mathrm{Rx})$. All the atmospheric conditions for composite links were considered to allow for the link margin and uplink power control to compensate for the losses experienced by the broadband VSAT.

The NigComSat ground facility and Nigcomsat-1R satellite were utilised for this study, with the following parameters: a Nigcomsat-1R orbital position of $42.5^{\circ} \mathrm{E}$, uplink frequency of $14 \mathrm{GHz}$, downlink frequency of $12 \mathrm{GHz}$ and Horizontal/Vertical polarisation. The measurement setup comprised two units of independent VSATs co-located in the same rain cell. These independent units were as follows: a beaconreceiving terminal on receive-only mode and broadband terminal for transmit and receive channels in the DVB-S2 network operating in a time division multiple access (TDMA) scheme with other VSATs [11].

Table 4 presents the receiving antenna parameters used for both the beacon and broadband. The beacon VSAT was configured to receive only for satellite downlink, while the broadband VSAT was configured for both transmit and receive modes used for real-time IP services. This was to allow for the measurement of rain attenuation in normal operations compared with the beacon narrowband signal. Figure 3 shows the outdoor unit of a VSAT antenna connected to the indoor unit via an interfacility link using coaxial cable (cat6) to minimise the cable loss. Figure 4 shows the beacon receiving terminal schematic.

Table 4. Earth Station Parameters for the Beacon Continuous Wave (CW) and Broadband Carrier

\begin{tabular}{lll}
\hline Antenna & Parameter & Values \\
\hline & Type & Offset \\
& Diameter & $1.8 \mathrm{~m}$ \\
VSAT & Frequency & $12.518 \mathrm{GHz}$ \\
Antenna & Polarisation & Vertical \\
& Azimuth & 102 \\
& Latitude & $7.14^{\circ} \mathrm{N}$ \\
& Longitude & $9.02^{\circ} \mathrm{E}$ \\
& Altitude & $334 \mathrm{~m}$ \\
\hline
\end{tabular}




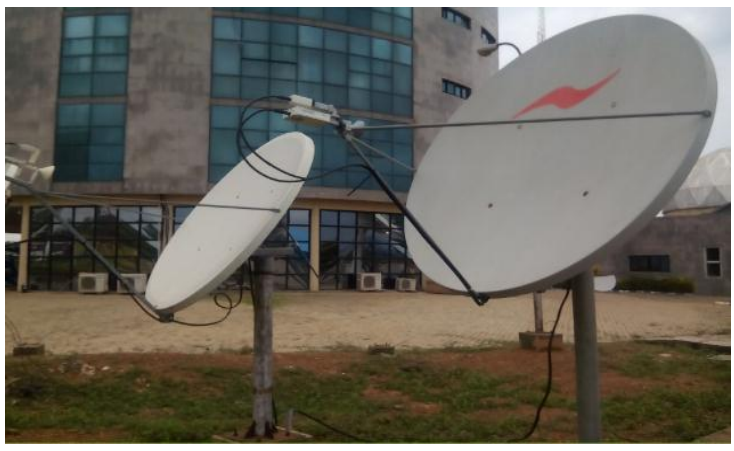

Figure 3. Broadband VSAT Outdoor Unit Receiving on the Ku-Band Frequency from Nigcomsat-1R

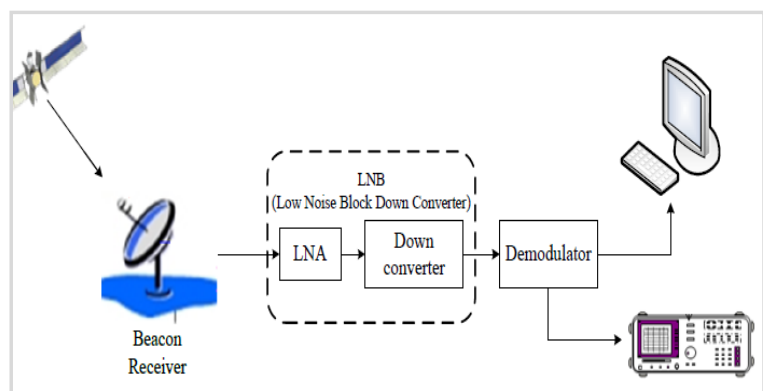

Figure 4. Ku-Band Beacon Receiver Setup Connected to the Nigcomsat-1R Spectrum Analyser.

The beacon signal-receiving terminal was installed with a clear line of sight (LOS) to the satellite field of view. The maximum received $\mathrm{CW}$ carrier was monitored on a spectrum analyser connected to an RF signal splitter, as shown in Figure 4. The outdoor unit was fitted with a low noise block (LNB) to receive the satellite signal and convert it to an intermediate frequency (IF) of $1500 \mathrm{MHz}$. The signal was then amplified as depicted in Figure 5a under a clear sky with the broadband and beacon carriers; Figure 5b shows only the beacon during a rain event, when the broadband was completely absorbed due to rain attenuation.

The broadband VSAT signal was observed on the spectrum analyser (Figure 5a); it is typically used for internet connectivity with several carriers sharing a transponder [12]. The rain-induced attenuation measured from this terminal was used as an input for the link design. Figure $5 b$ confirms the performance of the beacon during rain events. The performance of the satellite links in Figures 5a and 5b under a clear sky and wet/rain conditions, respectively, can be related to the rain effect and the level of attenuation experienced by the systems under testing.

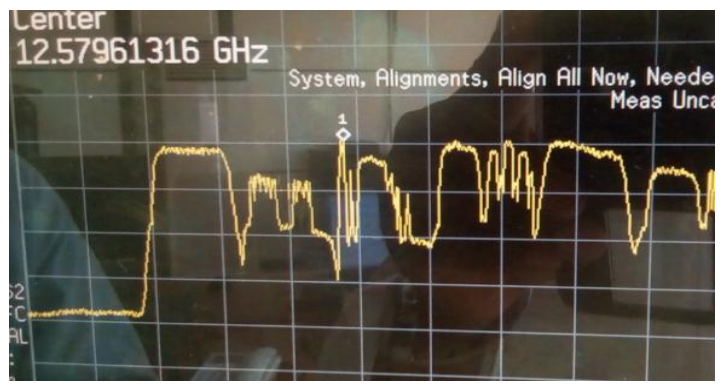

Figure 5a. Clear Sky Showing Multiple Broadband Carriers on Nigcomsat-1R Transponders and Beacon Signals in Delta Marker 1.

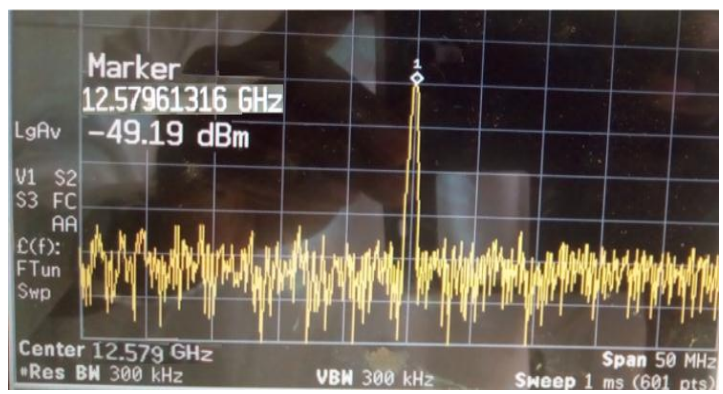

Figure 5b. Rain Event Showing No Broadband Carrier, with Only Beacon Signals on the Spectrum Analyser, with the Beacon in Delta Marker 1.

\section{RESULTS AND ANALYSIS}

From the simulation results, the ITU-R P.618-12 and Crane models both showed a clear divergence from one another, as well as the rain gauge-measured rain rate. While the Crane model showed relatively close agreement with the ITU-R model, both underestimated the rain rate for the ground station of the Nigcomsat-1R satellite; hence, the attenuation was also underestimated, leading to a lower link margin.

\subsection{Link Performance}

The overall performance of satellite communication networks is generally presented in terms of the $\mathrm{C} / \mathrm{N}$ ratio, illustrating the information quality, or the BER, video impairments and audio fidelity. Since rain attenuation increases with the frequency and rain rate, an additional fade margin is required based on the statistics of the local rainfall rate [13]. The observations from the spectrum analyser in Figure 5a show the carrier power above the noise level of $12.56 \mathrm{~dB}$ for the beacon signal (delta marker 1) and $12.02 \mathrm{~dB}$ for the 
broadband signal on a $10 \mathrm{~dB}$ per division scale. Figure 5 a depicts both the beacon and broadband signals at approximately the same level under clear sky weather conditions from the same transponder of Nigcomsat1R. However, during the rain event shown in Figure 5b, with the rain event lasting for about 1,200 seconds at a higher rate exceeding $100 \mathrm{~mm} / \mathrm{h}$, the broadband carrier is completely absorbed by the rain effect, while the beacon is still available. This shows the much higher capacity of the beacon to withstand the rain effect compared with the broadband carrier.

The extreme effect of rain attenuation on the broadband signal in tropical zones usually makes it impossible to receive the same signal when the $\mathrm{C} / \mathrm{N}$ drops by $6 \mathrm{~dB}$, as predicted by several rain attenuation prediction models, including the ITU-R P.837-7. Similarly, Figures 6 and 7 show the observations conducted on 14 June 2016 in terms of the status of the beacon and broadband signals under a clear sky, while Figures 8 and 9 present the rain's effects on both broadband and narrow band beacon signals measured on 15 June 2016.

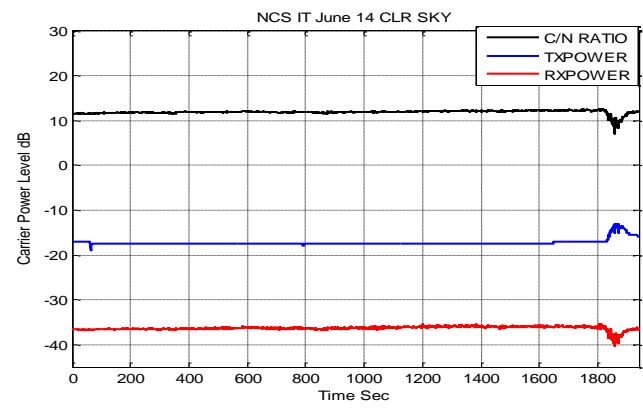

Figure 6. Clear Sky Broadband Signal with a Carrier-to-Noise Ratio (C/N) above $12 \mathrm{~dB}$.

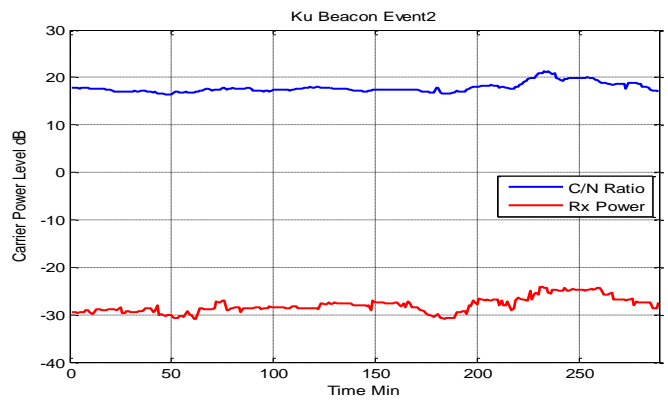

Figure 7. Clear Sky Narrowband Beacon Signal with Stability of $2 \mathrm{~dB}$.

Figure 6 shows the broadband signal's response to the atmospheric variation, while that of the beacon is shown in Figure 7. The link degradation for the broadband lasted up to 780 seconds, shown in both transmit and receive power level, while the narrow band beacon signal exhibited relative stability.

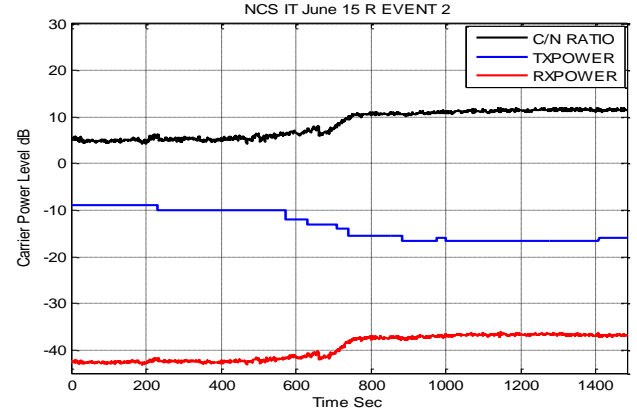

Figure 8. Broadband Signal with A Carrier-toNoise Ratio $(\mathrm{C} / \mathrm{N})$ of $5.68 \mathrm{~dB}$ Below the Threshold, with About 700 Seconds of Fade Condition.

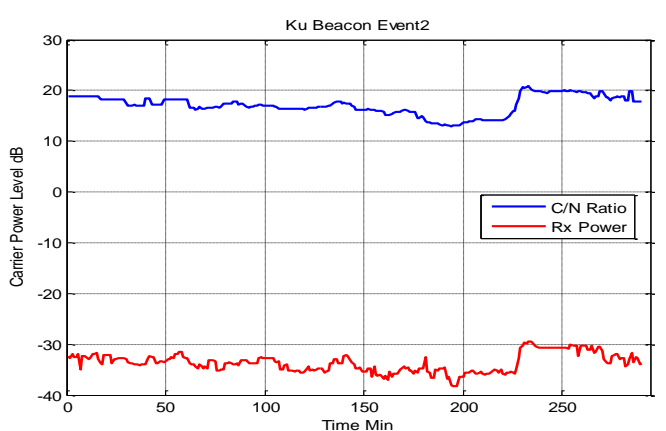

Figure 9. Narrowband Beacon Signal Sensitivity of 5 dB under A Rain Event.

The significance of the BW's capacity can be expressed in Equations 3 and 4 when a $1-\mathrm{Hz} \mathrm{BW}$ is applied to calculate the required $\mathrm{C} / \mathrm{N}$ for the threshold limit. The effect of the $\mathrm{BW}$ for the determination of the required $\mathrm{C} / \mathrm{N}$ shows the robustness of the BW power shown, as illustrated in the broadband signal's performance. This is shown in Figures $5 \mathrm{a}$ and $5 \mathrm{~b}$ for power as a ratio of the satellite transponder for a high data rate transmission, as expressed by Equation 5:

$$
\frac{C}{N_{\operatorname{Re} q}}=\frac{E_{b}}{N_{o}}+10 \log \left(\frac{T_{R}}{B_{w}}\right),
$$


For a unity BW in the case of a beacon signal, the carrier-to-noise spectral density becomes

$$
\frac{C}{N_{o}}=\frac{E_{b}}{N_{o}}+10 \log \left(T_{R}\right)
$$

The overall $\mathrm{C} / \mathrm{N}$ can be calculated from

$$
\frac{C}{N}=\frac{C}{N_{o}}-10 \log \left(B_{w}\right)_{O c c}
$$

Equation 5 also shows the significance of the BW requirements $\left(B_{w}\right)$ in broadband services, which is not critical in the beacon signals of a $\mathrm{CW}$ carrier. The $T_{R}$ determines the overall throughput and quality of service, which is also a critical variable for the trade-offs between the transponder BW, power and modulation scheme. Table 5 presents the atmospheric effects on both signals.

Table 5. Beacon and Broadband Signals' Response under Clear Sky and Rain Event Losses

\begin{tabular}{cccccc}
\hline Variable & Clear-sky & Rain & Clear-sky & Rain & Rx loss \\
& $\mathrm{C} / \mathrm{N}(\mathrm{dB})$ & $\mathrm{C} / \mathrm{N}(\mathrm{dB})$ & $\mathrm{Rx}(\mathrm{dB}$ & $\mathrm{Rx}(\mathrm{dB})$ & \begin{tabular}{c}
$\mathrm{dB}($ clear sky/rain) \\
\hline Beacon signal
\end{tabular} \\
18.35 & 15.82 & -28.46 & -35.49 & $\mathbf{7 . 0 3}$ \\
Broadband signal & 13.10 & 5.68 & -28.19 & -45.61 & $\mathbf{1 7 . 4 2}$ \\
Variance & $\mathbf{5 . 2 5}$ & $\mathbf{1 0 . 1 4}$ & $\mathbf{0 . 2 7}$ & $\mathbf{1 0 . 1 2}$ & $\mathbf{1 0 . 3 9}$ \\
\hline
\end{tabular}

\subsection{Analysis}

Table 5 shows the performance of both signals under clear sky and rainy conditions, with a broadband signal attenuation of about $17.42 \mathrm{~dB}$; the beacon only experienced a loss of $7.03 \mathrm{~dB}$. Similarly, the observed broadband received signal variance compared with the beacon was $10.12 \mathrm{~dB}$ due to the rain effect. This confirmed the relation in Equation 5 as a factor necessary for the quality of service and performance of satellite links. The threshold limit is the required $\mathrm{C} / \mathrm{N}$ (C/NReq), expressed in terms of energy per bit to $T_{R}$, and the $\mathrm{BW}$. The $\mathrm{C} / \mathrm{N}$ variance of $10.14 \mathrm{~dB}$ and received signal power $(\mathrm{Rx})$ of $10.12 \mathrm{~dB}$ between the clear sky and rain events calls for a serious propagation impairment mitigation technique to be considered. The difference between the beacon and broadband downlink signal was used to estimate the attenuation on the uplink signal due to the local atmospheric attenuation.

\section{CONCLUSION}

This study revealed that the sizing of link budget parameters requires a wide range of factors to be considered, especially when different applications are to be utilised. The measurement conducted for this evaluation is in accordance with Equation 5. This points to the fact that a beacon signal (narrowband) can perform much better in bad weather, due to its higher gain compared with broadband. The narrow, focussed radio-wave beams of the high gain are optimal for long-distance communication due to the beacon's higher effective isotropic radiated power (EIRP) and lower losses [14] compared with the broadband signal. The use of narrow band signals for rain attenuation analysis for estimation of link margin application in VSATs will require further study in terms of comparisons and different applications. The rain rate determines the level of attenuation and power margin for link calculations; underestimation of rain attenuation will result in less margin allocation, which may not adequately compensate for this loss. Hence, there is a need for more robust propagation impairment mitigation techniques (PIMTs).

\section{ACKNOWLEDGEMENTS}

This work is been funded by Ministry of Education Malaysia (MOE) and UTM under "HICOE Research Grant" Vot. No. R.J.130000.7823.4J221, the authors are very grateful for all the support and encouragements.

\section{REFERENCES}

[1] O. O. Obiyemi, et al, "Rainfall variability and impact on Communication Infrastructure in Nigeria" Journal of Telecommunications, vol.25 issue 1, may, 2014. 
[2] J. S. Mandeep, et al, "Rainfall effect on Ku-band satellite link design in rainy Tropical Climate" Journal of Geographical Research" vol. 113, 2008.

[3] A. D. Panagopoulos, et al, "Satellite communications at $\mathrm{Ku}, \mathrm{Ka}$, and V-bands: Propagation impairments and mitigation techniques, ” IEEE Communications Surveys Tutorials, vol. 6, no. 3, pp. 2-14, 2004.

[4] A. Idrissa, et al, "Implementation of Adaptive Coding and Modulation for Satellite Communication links in heavy rain region: an operator's perspective" Journal of Engineering and Applied Sciences (ARPN), Vol 11 No 12, pp.7858-7861, June, 2016

[5] ITU-R P.618-12 "Propagation data and prediction methods required for the design of Earth-space telecommunication systems" 2015.

[6] ITU-R P.837-7 "Characteristics of precipitation for propagation modelling" 2013. International telecommunication Union Recommendation on Radio Conference, Geneva.

[7] D.Y. Choi, et al, "Comparison of measured rain attenuation in the $12.25 \mathrm{GHz}$ band with predictions using ITU-R model" International Journal of Antenna and Propagation, Hindawi Publishing corporation, 2012.

[8] Avadh Nandra et al, "Optimization of Satellite Link Design" IEEE International Conferences. DOI: 10.1109/SECON. 2008

[9] Selvachandran Kogulan "Influence of weather on Beacon power level", www.sourceforge.isae.fr/projects 2015.

[10] Félix Cuervo et al, "Ka-band propagation campaign in Malaysia - first months of operation and site diversity analysis" IEE Explore - Antennas and Propagation (EuCAP), 2016.

[11] L. Gang "Method of TDMA HighlyMobile SatcomStation Network Synchronization" 4th International Conference on Informatics, Environment, Energy and Applications Volume 82 of IPCBEE 2015.

[12] J. Border "Performance Enhancing Proxies Intended to Mitigate Link-Related Degradations" International Network Working Group NASA Glenn Research Center Montenegro, 2007.

[13] G. Immadi, et al, "Measurement of Rain Attenuation for $\mathrm{Ku}$ Band satellite signal in tropical environment using DAH, SAM models" Journal of engineering and applied sciences, Asian Research Publishing Network (ARPN), vol.10, No. 4, March 2015.

[14] Kaneko, Kazuma, et al. "An evaluation of flexible frequency utilization in high throughput satellite communication systems with digital channelizer." Communications (ICC), 2017 IEEE International Conference on. IEEE, 2017.

\section{BIOGRAPHIES OF AUTHORS}
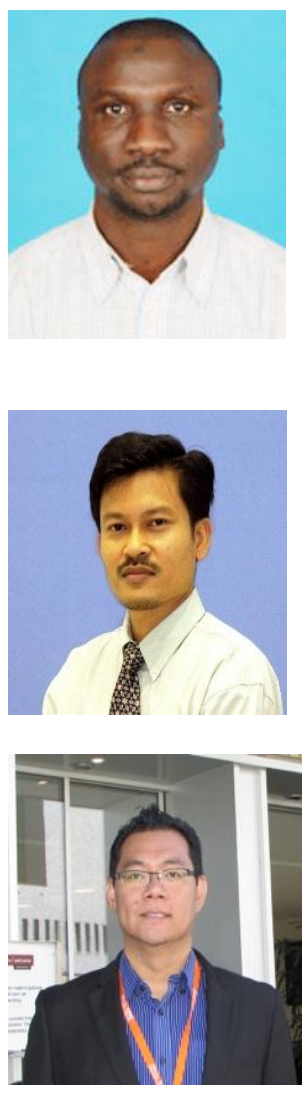

Idrissa Abubakar, Obtained (B.Eng) - Degree in Electrical \& Electronics, University of Maiduguri, Nigeria 2001. Postgraduate Certificate in Space System \& Communication Satellite Payload, from China Academy of Space Technology (CAST), Shenzhou Institute, Beijing, 2007. Master of Engineering Degree (M.Eng) in Electronic and Information Engineering, Beihang University, Beijing China, 20012. Research study in Space to Earth Satellite Propagation under the supervision of Prof. Madya Dr. Jafri Din. Worked at Nigerian National Space Research and Development Agency, Abuja. Currently working with Network Operations Center and Satellite Applications Division of Nigerian Communications Satellite (NigComSat) Ltd, Also worked with as field engineer with InterC Network Nigeria PLC, a Mobile/Fixed Wireless Telecommunications Company offering both GSM and CDMA wireless services in Nigeria.

Jafri Bin Din received his BSEE in Electrical Engineering from Tri-State University, Indiana USA in 1988 and his Ph.D from Universiti Teknologi Malaysia, Johor, Malaysia in 1997. He has been Head of Departments, Undergraduate Academic Manager Deputy Dean (Development) in Faculty of Electrical Engineering (FKE) UTM from 2008 till 2013. He is currently the Deputy Director of Wireless Communication Center (WCC) UTM. His research activities have been correlated to the field of radio wave propagation, satellite propagation and communications, High Altitude platform stations (HAPS), Satellite TV broadcasting, Weather Radar and sound technique for fisheries Industry.

Hong Yin Lam received the M. Eng. and the Ph.D. degrees in electrical engineering and telecommunication from the Universiti Teknologi Malaysia (UTM), Johor, Malaysia, in 2009 and 2013, respectively. He then served as a postdoctoral fellow in the Department of Communication Engineering (UTM), Johor, Malaysia. He is currently a lecturer at Faculty of Engineering Technology, Universiti Tun Hussein Onn, Malaysia, since 2007. His research activities have been relative to the field of radio wave propagation through the atmosphere, with specific focus on rain (rain drop size distribution and structures characterization) for propagation applications. Lam is a recipient of the Young Scientist Awards at the International Symposium on Antennas and Propagation (ISAP), Japan, in 2012, and Asia Pacific Radio Science Conference, Taiwan, in 2013. 